\title{
Roots of Miscommunication
}

\section{Elena Schmitt University of South Carolina}

\begin{abstract}
This paper proposes an account for the problem of miscommunication observed between native and non-native speakers of the English language. The analysis of interviews has shown that monologues produced by Russian speakers of English are structurally different from American monologues. A system based on the markedness theory was developed in order to account for the differences and provide a guide for teaching discourse skills in an ESL classroom It is suggested that universally sentences can be broken down into organizational features. This means that just like sounds, utterances can be found in polar opposition. The order in which utterances marked by these features are put together, represents the unmarked organizational structure of a monologue in a given language. The data received form the interviews indicates that Russian speakers of English do not acquire the unmarked American structure because they are not aware of the existing differences.
\end{abstract}

\section{Introduction}

Every person who had contact with non-native speakers of his/her language experienced some degree of frustration caused by the non-native interlocutor's prolonged, seemingly pointless utterances which quite often lead to irritation and lack of desire to continue the conversation on the part of the native speaker of the language. As a foreign language instructor I have often encountered this type of situation where even advanced students have problems in communication with the native speakers of the Target language (TL). The major difficulty is that native speakers of the TL lose interest in what the students have to 
say before they finish. In order to help my students to overcome this problem I carried out a study of naturally occurring monologues of the native speakers of English, native speakers of Russian, and non-native speakers of English. The analysis and comparison of the recorded data produced striking results that allow the correction of the communication problem quite easily within a classroom setting.

\section{Background}

The starting point for formulating a hypothesis to explain why the described problems occur was the theory of Relevance developed by Sperber and Wilson (1986). Among the many important aspects this theory suggests is the principle of cooperation, i.e. communication partners assume that they both are cooperating on working out the implicatures of the conversation and all the contributions to the conversation are relevant. My hypothesis regarding the existing obvious lack of interest on the part of the native speaker in the nonnative interlocutor's utterances is that native speakers have to put so much effort into understanding what is relevant about the non-native interlocutor's conversation that they feel it is not worth the trouble (Wilson and Sperber, 1992). One of the evident explanations might be that speakers of different languages have varying ideas of what is relevant in conversation. In other words, relevance which all humans aim at according to the Relevance Theory (Sperber and Wilson, 1986) is culture-specific. Since the idea of relevance is abstract and acquired with the language, it would be very difficult, if not impossible to teach foreign language students about what is relevant in their TL.

However, there is an alternative to this account which takes into consideration the differences in the organizational structure of monologues in various languages and cultures. If the difference is structural, it can be overcome more easily than attempting to reset a cognitive parameter such as relevance in a second language setting. I will prove in this paper that the explanation dealing with the structural organization of texts is more plausible than the account based on different views of what is relevant.

In order to limit this research and make its results applicable to practical teaching methodology, all the analysis and comparison of native and non-native monologues will be confined to one of the aspects of the markedness theory - the theory of distinctive features.

The theory of markedness was originally developed by Roman Jakobson and the Prague Circle. It mainly concerned the phonemic opposition of sounds, based on the opposition of distinctive features (Jakobson, 1956). Later the theory of markedness was applied to syntax, semantics, and discourse analysis. Each approach to markedness or rather each application of markedness to various linguistic disciplines is based upon the feature system of the phenomenon under consideration. Sounds, for example, can be marked or unmarked in respect to voicing; speech categories can be marked or unmarked in respect to presence or absence of nominal features etc.

Discourse, as a whole, is comprised not only of sentences or utterances in isolation discourse is a sentence or a group of sentences uttered under appropriate circumstances, in 
a certain sequence, with a certain context. It is in this sense that we can talk about the organization of discourse.

Every culture has its own rules for structural organization of texts. (The term 'text' is used here in reference to any sequence of utterances.) For example, Western cultures require the presence of a thesis or a theme in a text, i.e. the most relevant and prominent part of a text which is presented as a proposition and later can be supported or defended in argument. Oriental cultures, on the other hand, avoid thesis in their texts, expressing relevance by other means. However, regardless of the organization, there is a common ground in all cultures - sentences are generally used for building texts. Universally sentences can be broken down into organizational features, such as [+opening] for sentences that can be used as opening phrases, [+thesis] for those sentences that can be used as thesis, theme of the text, [+information] for the sentences used to develop the thesis. This means that just like sounds are "enabled to serve as vehicles of meaning by the fact that they are opposed to one another" (Battistella, 1990), utterances too, can be found in polar oppositions, which contribute to better understanding of their intended meaning. For example, some sentences within discourse are marked as [+opening], like 'Listen', 'How is life?'; others are marked as [-opening], for instance 'Good bye', or 'It's good talking to you". A whole feature system can be worked out for the various sentences of a particular language. But many of the organizational features, as mentioned above, can be used universally, thus making the task of structure identification much easier. It is quite safe to suggest that 'Good bye' would be [-opening] in every language, while 'How are you?' is going to be [+ opening]. Sentences like, 'It's good to see you' can be either $[+]$ or $[-]$ opening depending on the context.

Based on this information, we can formulate the main question of this study: Is the organizational structure of conversation affected by the speaker's native distribution of discourse sentence features? In other words do speakers of English as a second language organize the structure of their conversation differently from native English speakers and if so, is this due to the transfer of the feature structure of sentences in their native language or due to other reasons, like different ideas of what is relevant in discourse?

\section{Procedure and Control Group}

In order to resolve this problem it is necessary to take a look at the unmarked organization of conversational monologues for the languages used in this study, Russian and English. This research compares the organization of monologues, produced in a casual atmosphere by native English speakers and by Russian speakers of English. All the informants are women ages 25 to 40 . They have a college education and the Russian informants have lived in the United States for no less than four and a half years. All the informants were asked two questions. One question was concrete. It was based on an event - the speaker's vacation. The other question was abstract. It involved a discussion of reasons the abortion is a controversial issue. It is not by chance that the informants had an opportunity to talk about 
concrete and abstract topics. The reason for this was to elucidate non-native speakers' ability to produce the same structures in both types of monologues and to observe the organizational differences that the speakers may demonstrate between abstract and concrete topics, which have varied level of difficulty for non-native speakers: usually it is easier to communicate a concrete topic, than an abstract one.

In order to be able to compare the discourse structure of non-native speakers of English to native discourse we first need to establish the major characteristics of English discourse. The following interview represents a typical monologue produced by a college-educated American woman:

I. So, Patty, tell me about your vacation. What did you do last summer?

P. Well, my vacation was very short. I didn't have what you call a vacation. My friend came to visit me from Argentina. I taught this summer. I had a couple of weeks in between the sessions. So I guess my vacation would consist... Oh, I went for one week to Myrtle Beach. We went swimming and we went out to eat, and we went out dancing. And we stayed there for two nights and three days. Then we also went to Charleston for one day. And then I also went home to Alabama which was also a kind of vacation. So I stayed there for five days. And it was at the time of my birthday. So I had a birthday party. I had a nice summer.

From the text presented here it becomes evident the monologue starts with a thesis: 'Well, my vacation was very short' which is followed by a set of information sentences that develop the thesis, and eventually there is a concluding sentence: 'I had a nice summer', which in a way is a restatement of the thesis.

The same organizational structure is represented in the next monologue on the abstract abortion topic.

I. Why do you think that abortion is such a controversial issue today?

P. Well, probably, one of the big reasons it is so hot is because we can't define when life begins. Some people believe that life begins at birth and others believe that life begins at conception. And for those who believe that life begins at birth an abortion is not a murder. But for those who believe that life begins at conception, abortion is murder. And so it gets hot and tense between people because basically people tell their friends who believe in abortion that they believe in murder and the people who are for abortion who are pro-abortion believe that people who don't believe in abortion are taking away their personal freedom. So it's a hot issue because we can't define when life begins.

Again, the speaker starts with a thesis: 'Well, probably on of the big reasons it's so hot is because we can't define when life begins'. She goes on to the information sentences which develop the thesis and finishes up with a concluding phrase: 'So it's a hot issue because we 
can't define when life begins'. Just like in the previous monologue the concluding sentence appears to be a restatement of the thesis.

Thus, based on these examples and other data recorded from three more American women, we can summarize by saying that American speakers use the following organization of texts:

- thesis that is incorporated into the opening;

- sentences that develop thesis, i.e. information sentences;

- conclusion, which is in a way restatement of the thesis.

If we try to identify these parts of discourse with the help of the feature specification, the following distribution of the monologic discourse in American English will emerge:

$$
\begin{array}{crr}
\text { S1 [+ opening } & \text { S2 [-opening } & \text { S3 [-opening } \\
+ \text { thesis } & \text {-thesis } & + \text { thesis } \\
\text { - info] } & \text { +info] } & \text {-info] }
\end{array}
$$

where $\mathrm{S}$ stands for a group of sentences marked by the same features and numbers 1,2,3 are used for the convenience of reference to those groups.

Now it is necessary to establish the feature pattern of the Russian monologic discourse based on interviews of several Russian women of the same age and education as their American counterparts. The following is an example of one such interview on abortion:

I. Аня, скажи мне пожалуйста, почему ты думаепю, что проблема Anna, please tell me why you think that the issue

абортов является очень противоречивой в США? of abortions is so controversial in the USA?

A. Мне кажется, что аборт - это самое трудное решение, которое I believe, that an abortion is the most difficult decision, which

женшщына может принять. Ведь это риск и для женщины и для ребёнка. [1] a woman can make. It involves risk for both the woman and child.

Мы с друзьями часто говорим об абортах - это интересная тема. My friends often talk about abortion - it's an interesting topic.

Американщы часто не понимают, что посторонние люди не могут регптть, Americans often don't understand, that strangers cannot decide

нужен ли аборт в каждом конкретном случае. Это решение, 
whether the abortion is necessary in each case. This is a decision

которос взвешивается и из-за которого люди не спят ночами.

which people weigh very carefully and spend sleepless nights.

Поэтому нельзя сказать, что аборт делается только из-за того, что [3]

That's why we cannot say, that abortion is done only because

люди пе думали о последствиях или были безответствепты.

people didn't think about the consequences or were irresponsible.

Я думаю, что в большинстве случаев аборты - это трагедия для жкеншины, [3]

I think, that in the majority of cases abortion is a tragedy for a woman,

а совсем не лёгкий выход из положения. Но всегда интересно знать, что стоит за абортом.

not just an easy way out. But it's always interesting to know what is behind each abortion. [4]

From this monologue we can see that Russian has a different discourse structure than English. Namely, Russian speakers do not start with a thesis. Their opening group of sentences, marked [1], can be identified as [+opening, -thesis, -info]. The thesis is stated much later in sentence 4, marked [2], which can be discussed in the feature terms as [opening, +thesis, -info]. The next group of sentences, marked [3], develop the thesis and fully correspond to the English group marked with features [-opening, -thesis, +info]. The last group of sentences, marked [4], is concluding. It can be represented as [-opening, thesis, -info].

Thus only those sentences that develop the thesis coincide in both languages with respect to features [-opening, -thesis, + info. Other types of sentences employed at the beginning and at the end of texts vary.

To summarize, the features of the sentences that constitute English and Russian monologues are distributed in the following way:
English
+ thesis
-info]
Russian
1. $[$ +opening
[+opening
-thesis
- info]
2.

$$
\begin{aligned}
& \text { [-opening } \\
& + \text { thesis } \\
& \text {-info] }
\end{aligned}
$$




$\begin{array}{ll}\text { 3. } \begin{array}{l}\text { [-opening } \\ \text {-thesis } \\ \text { +info }\end{array} & \begin{array}{l}\text { [-opening } \\ \text {-thesis } \\ \text { +info] }\end{array} \\ \begin{array}{l}\text { [-opening } \\ \text { +thesis } \\ \text {-info] }\end{array} & \begin{array}{l}\text { [-opening } \\ \text {-thesis } \\ \text {-info] }\end{array}\end{array}$

This schematic interpretation of the control group data, shows that the main difference in the Russian and American discourse organization lies in the fact that the opening sentences of Russian do not carry the feature [+thesis]. Americans, who are used to immediate exposure to the most relevant part of the text, consider their Russian interlocutors uncooperative and unwilling to come to the point since the thesis does not appear till much later in the text.

Overall, Russian speakers who acquire English must change their pattern of discourse organization to produce unmarked texts in English. This change should be done in the following way: steps two and one need to be collapsed, the opening sentence needs to carry the feature [+ thesis]. At the same time part four, the conclusion, needs to be connected to the thesis and thus acquire the feature [+thesis].

The following part of the paper will demonstrate the analysis of texts produced by Russian speakers of English. As a result of this analysis we will be able to establish whether the required discourse adjustment has been made or not. The implications that the theory of markedness and the established features of text organization have for the second language learners and instructors will be discussed.

\section{Analyses of monologues}

Ten Russian women were interviewed for the purposes of this analysis. All of them have lived in the United States from four to four and a half years. They have university degrees and a job which involves the use of the English language. Their age is between 28 and 45 . The only variable that is relevant here is their proficiency in the English language.

In terms of ACTFL proficiency levels they can be place into different categories from low-intermediate to the superior level. The reason for identifying the proficiency levels as a variable is to be able to draw distinctions based on the speaker's use of certain discourse structures due to their familiarity with the traditional American monologue organization or for other reasons. In order to limit the volume of this paper only four interviews, representing different levels of proficiency, will be discussed in detail.

The first interview that we are going to analyze was conducted with Fanya who is a low intermediate user of the English language. Fanya was asked the same two questions as the other speakers, about last year's vacation and the reasons for controversy of abortion. Below is the script of the interview, followed by the analysis. 
I. So, Fanya, tell me what did you do last summer?

F. I have friends in New London, in Baltimore. In Baltimore I have friends and relatives and have a trip to New London. And we had a good time. I spent two day with my friends. It's my more closer friends. It's my neighbors and we lived together 15 years. And then I met my friend in Baltimore. And I spent 2 days with friend and relative. And after Baltimore we went to North Carolina, Raleigh. And I saw my son for one day. And I came back. And I have a lot of pictures. And I have a lot of fun. I have a lot of memories. And I saw the pictures and I like them. I had a good time.

Notice that in answering the first concrete, and therefore simpler question Fanya starts with the introduction: "I have friends in New London, in Baltimore. In Baltimore I have friends and relatives." Then she goes to the thesis: "I have a trip to New London and we had a good time." And she ends up with a restated thesis or summary: "I had a good time."

Now let us look at her answers to the more abstract question on abortion issues:

I. Why do you think that abortion issue is very controversial? Why do people argue about it?

F. May be there are a lot of problems. May be it's religion. Many people, for Jewish people it is the Bible may be. Or the Orthodox. A woman can't killed the child. May be he is not born. But they can't do it, they can't take any medicine and they can't do any operation. And some men, a lot of people Baptists they also mean so that people can't do nothing. What God promised and take them so children they have. The people who more educated, understand more. They have may be more think about it. They think what people can't because it's social problem. Like people. Its depends on money if you have. Every child need take care for and here in America it's a lot of problems to grow up a child. So every family can plan how many children they can have. So I can't say what people who argue what abortion is. Against this abortion. They has meaning maybe they right. And another people also right. Everybody has a solution about this.

It is interesting that Fanya answers this more abstract question, starting directly with the thesis sentence: "May be there are a lot of problems. May be it's religion."

Before drawing any conclusions from Fanya's speech let us look at the next interview given by Irina, whose proficiency level can be described as intermediate.

I. Irina, tell me, please, about your vacation. What did you do last summer?

Ir. God, I love vacation. It was a wonderful summer. I didn't have any classes. All I did was just work. So I spent some time at home with my kids going out, swimming, going to the roller skating rink. I just enjoyed staying home so much. I was so happy I didn't have to go somewhere except work. But it's nothing. When 
you have to go to school and work, then only work is almost nothing, close to that. So I could spend some time with my family.

We can see once dgain that Irina starts with an opening sentence, which is marked [thesis] and only later moves to a [ + thesis] statement. However, her answer to the second question (the one about abortion) is structured differently. She starts out with a thesis and supports it with some [+ information] sentences:

I. Why do you think abortion is such a controversial issue?

Ir. I'd say that it's basically because of religion. Because people view their unborn child as a human being with the soul and life. And so abortion is like a killing which is of course the worst of the sins. So that's why it's so controversial. And people really, really believe in that. Absolutely. I think the woman has to have a choice. Of course I would rather recommend prevention, contraceptives. But I'm awfully against to prohibit abortions. I believe in free choice for everybody and second, if you officially prohibit it people will do it illegally and it will bring much more harm.

The next speaker is Basya, whose proficiency level can be described as advanced. It is remarkable that just like the other two speakers, she organized the answer to the first question according to the Russian structural pattern of the text, i.e. she started with the [ + opening, -thesis, -information] sentences, continued with a [+ thesis] part and ended with the traditional Russian [-opening, -thesis, -information] sentences.

I. -Basya, tell me how was your vacation? What did you do last summer?

B. -I like vacation. But I like vacation in the fall or in the spring because it's getting too hot in summer. We spent a week on the beach with my husband, my little son and my daughter. And then I was working. That's we went sightseeing, we saw Charleston and now we know pretty much about South Carolina, Charleston and the vicinity. Next time we are planning to go to the mountains. We don't go far away - South Carolina and now we go to North Carolina. I was calling the whole morning and found out a motel that is cheap. It's not really important where we'll spend the night. We've never been to the mountains. We'll drive a lot, we'll walk a lot. And hopefully we'll find some nice place.

Basya's answer to the second question was much less marked in respect to American discourse organization. She started with the [+thesis] sentence and finished with a [opening, -thesis, -information] phrase.

I. Why do you think abortion is such a controversial, such a hot issue? 
I think because a lot of people here are religious and from religious point of view to kill a baby is really cruel. And that's why at first it surprised us a lot. We saw a baby with this slogan that was against abortion. What this baby has to do with abortion? And we were really surprised. But because every Sunday they're going to church... See in Russia we were not so observant. People are not religious and as to my, as from my point of view I think that every woman will decide for herself. And I think if you ask some other people who immigrated from Russia, they will tell the same. Though I understand that to kill a child, but you have to understand a woman.

Finally, let us turn to the fourth interview given by the most proficient Russian speaker of English. Ashkhen was asked the same two questions. Her answer to the first question is very similar to the other informants' answers as far as the organization of the text is concerned.

I. Ashkhen, could you tell me a little about your vacation this past summer. What did you do?

A. Oh, summer vacation is my favorite. You can always do so much and travel a great deal. I love to travel and see new places. Last summer we traveled to Pittsburgh to see some of Taylor's friends and family. We also went to Charleston. It was a lot of fun. I like the architecture in downtown area. It reminds me of European style. Well, what else? We actually didn't do much. I worked a little bit. And then I was trying to get all the papers together for immigration. But that's about it. It was kind of boring vacation. I usually do more things in summer. I go swimming and exercise. And of course I like to travel a lot, usually. So summer is supposed to be fun.

From her answer to this question we can see, that like other non-native speakers she starts with a [+opening, -thesis, -information] sentence. She continues with the thesis and information and ends up with a sentence that can be described as [-opening, -thesis, information].

Ashkhen's second answer is quite different, though, from the other speakers'.

I. Ashkhen, why do you think abortion is a controversial issue?

A. I am definitely a pro-choice person. But I wouldn't argue with somebody who is pro-life, because I think it's up to any person to make such choice. I think this issue is very controversial because basically for pro-choice people it's the questions of freedom being taken away from them. and for pro-life people it's you're killing a human being. And when two groups of people look at the same issue from two completely opposite points of view then the clash of ideas is inevitable and there's no way to avoid controversy. But as far as choices are concerned I'm convinced that no point of view should be imposed on anyone and people who' re considered 
adults and are responsible for what they do should have a choice. And I don't think that they should justify what they are doing.

The speaker follows the pattern of the Russian text organization instead of starting with the [+ opening, +thesis] sentence like the less proficient speakers did. The possible explanation is that despite her high level of proficiency in English, she is not consciously aware of the differences that exist between the organizational structures of the two languages.

The interviews can be summarized in the following way. First of all the structural organization of the monologues produced by non-native speakers of English differs in correlation with their proficiency level and the difficulty of the questions asked. The following are the feature representations of the structures of monologues.

\begin{tabular}{|c|c|c|c|c|c|}
\hline \multicolumn{2}{|c|}{ Intermediate level } & \multicolumn{2}{|c|}{ Advanced level } & \multicolumn{2}{|c|}{ Superior Level } \\
\hline concrete & abstract & concrete & abstract & concrete & abstract \\
\hline $\begin{array}{l}\text { 1. I +opening } \\
\text {-thesis } \\
\text {-info] }\end{array}$ & $\begin{array}{l}\text { [ +opening } \\
\text { + thesis } \\
\text { - info] }\end{array}$ & $\begin{array}{l}\text { [ topening } \\
\text {-thesis } \\
\text {-info] }\end{array}$ & $\begin{array}{l}\text { [+opening } \\
\text { +thesis } \\
\text {-info] }\end{array}$ & $\begin{array}{l}\text { [ +opening } \\
\text {-thesis } \\
\text {-info] }\end{array}$ & $\begin{array}{l}\text { [ + opening } \\
\text {-thesis } \\
\text {-info] }\end{array}$ \\
\hline $\begin{array}{l}\text { 2. [-opening } \\
\text { +thesis } \\
\text {-info] }\end{array}$ & $\begin{array}{l}\text { [-opening } \\
\text {-thesis } \\
+ \text { info] }\end{array}$ & $\begin{array}{l}\text { [-opening } \\
\text { + thesis } \\
\text {-info] }\end{array}$ & $\begin{array}{l}\text { [-opening } \\
\text {-thesis } \\
+ \text { info] }\end{array}$ & $\begin{array}{l}\text { [-opening } \\
+ \text { thesis } \\
\text {-info] }\end{array}$ & $\begin{array}{l}\text { [-opening } \\
\text { + thesis } \\
\text {-info] }\end{array}$ \\
\hline $\begin{array}{c}\text { S3. [-opening } \\
\text {-thesis } \\
+ \text { info }\end{array}$ & & $\begin{array}{l}\text { [-opening } \\
\text {-thesis } \\
+ \text { info] }\end{array}$ & & $\begin{array}{l}\text { [-opening } \\
\text {-thesis } \\
\text {-info] }\end{array}$ & $\begin{array}{l}\text { [-opening } \\
\text {-thesis } \\
\text { +info] }\end{array}$ \\
\hline $\begin{array}{c}\text { S4. [-opening } \\
\text { +thesis } \\
\text {-info] }\end{array}$ & $\begin{array}{c}\text { [-opening } \\
\text { +thesis } \\
\text {-info] }\end{array}$ & $\begin{array}{l}\text { [-opening } \\
+ \text { thesis } \\
\text {-info] }\end{array}$ & $\begin{array}{l}\text { [-opening } \\
\text {-thesis } \\
\text {-info] }\end{array}$ & $\begin{array}{l}\text { [-opening } \\
\text {-thesis } \\
\text {-info] }\end{array}$ & $\begin{array}{l}\text { [-opening } \\
\text {-thesis } \\
\text {-info] }\end{array}$ \\
\hline
\end{tabular}

\section{Results and implications}

From the above summary one can see that the results are quite varied. On the one hand, the answers of the lower-level speakers to the abstract questions follow the same structure as the Americans' responses. On the other hand, speakers of all levels produced answers to the concrete questions utilizing the Russian monologue structure. The speaker of the superior level organized her monologues in both concrete and abstract answers according to the Russian schema of conversation, i.e. she started with an introduction instead of a thesis and concluded the speech without restating the thesis.

Generally, these results show that there exists a difference in the structural organization of monologues in the two languages. The question that remains is whether the speakers 
perceive this difference and if so why the distribution of the data is so divided? Surely, if the intermediate speakers are able to conform to the American structure of monologues, this can be expected of the advanced and superior users of the language. There must be some way to account for why speakers switch back to their native textual structure when they are more proficient in the language. Since all the informants came up with the thesis and produced relevant answers, the idea of relevance being culture-specific is ruled out. My hypothesis is that the explanation lies in the profoundness of the knowledge of the speakers. Those who do not have a large vocabulary and strong grammar skills tend to go straight to the point and express their ideas as soon as they can, using a minimum amount of the available language. They seem to have found a 'shortcut' to explain their view point. On the other hand, those whose vocabulary is large and who feel confident with the language, produce more text and organize their ideas in the way familiar from their native language. While this study did not specifically test the informants on the vocabulary and grammatical competence, the correlation between the level of proficiency and the amount of language used can be established in a further investigation. This explanation, however, deserves attention because it indicates that even more sophisticated speakers of English as a foreign language have not been taught the unmarked discourse structure of the target language.

In the introduction it was pointed out that it is essential for learners to be able to produce the unmarked monologues in the unmarked circumstances (Myers-Scotton, 1995) in order to sustain communication with native speakers of the target language. The need for the unmarked use of the TL is important for various pragmatic and social reasons. Pragmatic reasons include the relevance issue. People with an American cultural background have difficulty finding relevant implicature in the introductions which do not carry information or thesis. In other words, such introductions are marked for American listeners, but they are produced under the unmarked circumstances. Americans do not understand the need for the marked discourse and assume that the speaker is being uncooperative. This assumption can result in the broken communication, hostility, and other adverse social effects. Hence it is necessary to draw attention of the students to the differences that exist between their native discourse structure and the discourse organization of the target language.

To summarize, this study answered two main questions: first, is the concept of relevance culture-specific and as such interferes with communication between speakers of different languages? Second, are students of a TL aware of the structural differences that exist between the organizational systems of their native and target languages? The answer to the first question is that by and large the cultures studied (Russian and American) have the same or similar ideas of what is relevant in the discourse. Therefore, the differences in the organization of the monologues can be accounted for on a structural basis. This brings us to the answer to the second question - the study showed that the students are not consciously aware of the existing structural differences and therefore have a hard time emulating the unmarked discourse organization of the TL. The conclusion is that it is necessary to point out the structural differences to the students and thus, prevent them from making communicative errors in the target language. 


\section{Works cited}

Battistella, E. Markedness: The evaluative superstructure of language. State University of New York Press, 1990.

Jakobson, Roman. Fundamentals of language. Mouton, 1956.

Myers-Scotton, C. Social motivations for code switching. Clarendon Press. Oxford, 1995.

Sperber, D, and Deidre Wilson. Relevance: communication and cognition. Cambridge: Harvard University Press, 1986.

Wilson, D. and Dan Sperber. "On verbal irony." Lingua 87 (1992): 53-76. 